\title{
Measuring evolution of income-related inequalities in health and health care utilization in selected Latin American and Caribbean countries
}

\author{
Gisele Almeida ${ }^{1}$ and Flavia Mori Sarti ${ }^{2}$
}

Suggested citation

Almeida G, Sarti FM. Measuring evolution of income-related inequalities in health and health care utilization in selected Latin American and Caribbean countries. Rev Panam Salud Publica. 2013;33(2):83-9.

\begin{abstract}
Objective. To describe the methodology used to measure and explain income-related inequalities in health and health care utilization over time in selected Latin American and Caribbean countries.

Methods. Data from nationally representative household surveys in Brazil, Chile, Colombia, Jamaica, Mexico, and Peru were used to analyze income-related inequalities in health status and health care utilization. Health was measured by self-reported health status, physical limitations, and chronic illness when available. Hospitalization, physician, dentist, preventive, curative, and preventive visits were proxies for health care utilization. Household income was a proxy for socioeconomic status except in Peru, which used household expenditures. Concentration indices were calculated before and after standardization for all dependent variables. Standardized concentration indices are also referred to as horizontal inequity index. Decomposition analysis was used to identify the main determinants of inequality in health care utilization.

Results. Results of analysis of the evolution of income-related inequality in health and health care utilization in Brazil, Chile, Colombia, Jamaica, Mexico, and Peru are presented in separate articles in this issue.

Conclusions. The methodology used for analysis of equity in all six country research studies attempts not to determine causality but to describe and explain income-related inequalities in health status and health care utilization over time. While this methodology is robust, it is not free of errors. When possible, errors have been identified and corrected.
\end{abstract}

Key words Equity in access; equity in health; health systems; health policy; Latin America; Caribbean region.

Despite many challenges, a large number of countries in Latin America and the Caribbean (LAC) have implemented equity policies and programs aimed at improving the health status of and access

\footnotetext{
${ }^{1}$ Pan American Health Organization, Washington, D.C., United States of America. Send correspondence to: Gisele Almeida, almeidag@paho.org

${ }^{2}$ Modelagem de Sistemas Complexos, Escola de Artes, Ciências e Humanidades, Universidade de São Paulo, São Paulo, Brazil.
}

to health care for their most vulnerable population during past decades. While the region has seen remarkable progress in average health over the same period, there was no clear evidence whether the levels of inequity in health and health care that have plagued the region for so long have improved (1).

Since equity in health, utilization, and access to health care remains a common concern in the health agenda of most countries in this region (2), it is important to evidence its evolution and to understand which countries and related public policies were successful in reducing inequities. The significant increase in the availability of data from household surveys in LAC in recent years has contributed greatly to the analysis of equity and the increased evidence on equity in health systems in the literature. These surveys are available for download for 
free or for a modest fee and are a rich source of health, demographic, and socioeconomic data for the studies in this issue.

As the leading international public health organization in the Americas, the Pan American Health Organization promotes equity in access to timely and quality health goods and services among countries as the foundation of an equitable health system, and its evaluation and monitoring are regarded as key public health functions (3). Under the second wave of the EquiLAC project, which calls for systematic assessment of trends in health system equity in selected LAC countries, the Pan American Health Organization conducted an initial set of studies in six countries: Brazil, Peru. The main objective of these studies, published in this issue, is to measure and explain income-related inequalities in health status and health care utilization over time. This paper describes the studies.

\section{METHODOLOGY}

\section{Research study design}

All six country research studies published as part of this issue present descriptive research using trend study design, which examined changes over time with repeated cross-sectional databases of nationally representative household surveys (4). This type of study identifies changes over time in the populaChile, Colombia, Jamaica, Mexico, and methodology shared by these research

tion with new probability samples from that population for each year studied. It uses the same set of questions on health status, health care utilization, and demographic and socioeconomic characteristics, which are investigated at two or more points in time (5). For assessment of the direction of equity over time, each study used databases from at least two years: the latest available and three to six years before the latest data. Brazil and Chile examined these questions for three years, while Colombia, Jamaica, Mexico, and Peru used two years. Survey types included multipurpose household surveys with health questions (Chile), specialized health surveys (Mexico), specialized health modules in demographic surveys (Brazil and Peru), and qualityof-life health surveys (Jamaica and Colombia), as described in Table 1 (6-12).

\section{Data sources and samples}

The major source of data for the studies was large household surveys (Table 1 ), which are usually rich in data related to socioeconomic status and demographics. These surveys also provide data on health status, health care utilization, and others that can be used to explain variations in equity.

Given the heterogeneity of the surveys across countries in Latin America, in terms of type, frequency, and data collection, comparability among countries becomes challenging. To overcome this challenge and ensure better comparability, careful revision and selection of variables across surveys were performed.

TABLE 1. Household surveys used to analyze income-related inequality in health and health services in selected Latin American countries

\begin{tabular}{|c|c|c|c|c|c|}
\hline \multirow[b]{2}{*}{ Country } & \multirow[b]{2}{*}{ Reference } & \multirow[b]{2}{*}{ Database } & \multirow[b]{2}{*}{ Year } & \multicolumn{2}{|c|}{ Survey sample } \\
\hline & & & & Households & Individuals \\
\hline \multirow[t]{3}{*}{ Brazil } & 6 & Pesquisa Nacional de Amostra em Domicílio & 1998 & 90913 & 344975 \\
\hline & & Pesquisa Nacional de Amostra em Domicílio & 2003 & 107846 & 384834 \\
\hline & & Pesquisa Nacional de Amostra em Domicílio & 2008 & 118138 & 391868 \\
\hline \multirow[t]{3}{*}{ Chile } & 7 & $\begin{array}{l}\text { Encuesta de Caracterización Socioeconómica } \\
\text { Nacional }\end{array}$ & 2000 & 65036 & 252748 \\
\hline & & $\begin{array}{l}\text { Encuesta de Caracterización Socioeconómica } \\
\text { Nacional }\end{array}$ & 2003 & 68153 & 257077 \\
\hline & & $\begin{array}{l}\text { Encuesta de Caracterización Socioeconómica } \\
\text { Nacional }\end{array}$ & 2009 & 71460 & 246924 \\
\hline \multirow[t]{2}{*}{ Colombia } & 8 & Encuesta de Calidad de Vida & 2003 & 22949 & 85150 \\
\hline & & Encuesta de Calidad de Vida & 2008 & 13611 & 50545 \\
\hline \multirow[t]{2}{*}{ Jamaica } & 9 & Jamaica Survey of Living Conditions & 2004 & 1981 & 6683 \\
\hline & & Jamaica Survey of Living Conditions & 2007 & 1994 & 6613 \\
\hline \multirow[t]{2}{*}{ Mexico } & 10 & Encuesta Nacional de Salud & 2000 & 45827 & 187786 \\
\hline & 11 & Encuesta Nacional de Salud y Nutrición & 2006 & 47152 & 205877 \\
\hline \multirow[t]{2}{*}{ Peru } & 12 & Encuesta Nacional de Hogares & 2004 & 20866 & 91861 \\
\hline & & Encuesta Nacional de Hogares & 2008 & 22640 & 94547 \\
\hline
\end{tabular}

Table 2 describes the variables selected for the studies. The unit of analysis for all studies was the individual. Because of variation in the availability of data across countries, only individuals 18 years of age or older were included.

Measurement of health status was based on questions related to self-assessed health status (Chile, Colombia, Jamaica, and Mexico), self-reported chronic condition (Brazil, Colombia, Mexico, and Peru), and self-reported physical limitations (Brazil, Chile, and Mexico). Health care utilization measures included probability (at least one health care visit) and intensity of use (total number of visits or inpatient days) of services reported. Survey questions included visits to physicians (Brazil and Chile), general practitioners (Chile, Jamaica), specialists (Chile and Colombia), and dentists (Brazil, Chile, Colombia, Mexico, and Peru). Also included were measures of utilization of preventive and curative care (Colombia, Jamaica, Mexico, and Peru). Curative visits are defined here as those that originated due to a health problem, illness, or accident. Preventive visits are those with the sole purpose of disease prevention or health promotion.

A living standard variable was used to rank individuals in order to identify whether there is systematic variation in health or in the use of health care services across income groups. To achieve consistency in results, studies in all countries except Peru used household income as the ranking variable, measured as a continuous variable for aggregate per capita income of the household. The Peru study used household expenditures. The Mexican study benefited from availability of data and calculated income-related inequalities using household expenditures (value of goods and services purchased) and household wealth (a measure of household assets) as ranking variables in addition to household income.

Because income measures are known to overestimate the income of families with small children, since the needs of children and adults are equalized, an adult equivalence scale was used to adjust income variables. The Deaton approach (13) was used to calculate the equivalent scale in these studies, with the following equation:

$$
e_{h}=\left(A_{h}+\Phi K_{h}\right)^{\theta}
$$

where 
TABLE 2. Variables used to analyze income-related inequality in health and health services in selected Latin American countries

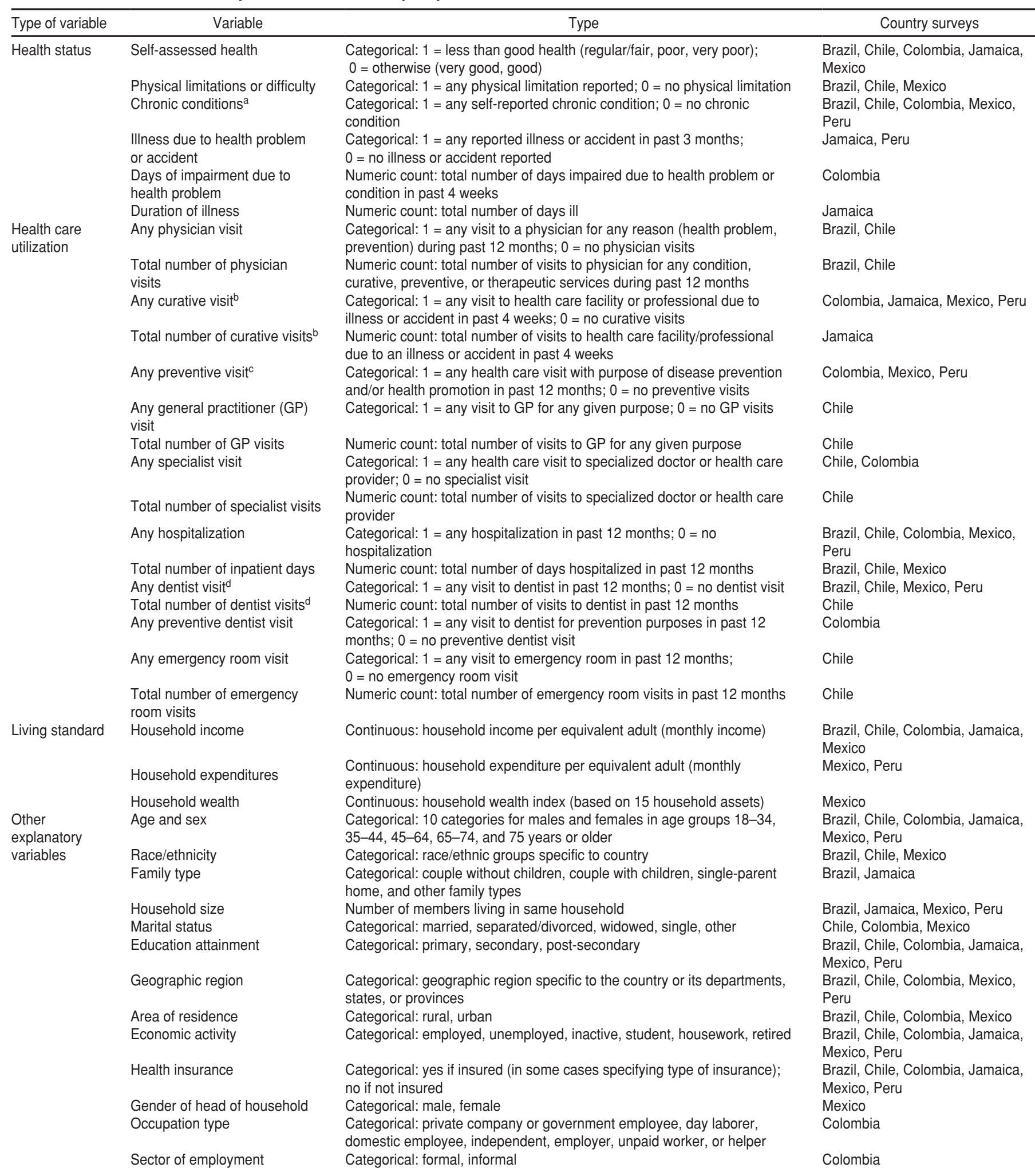

a Questions from 2003 and 2008 Pesquisa Nacional por Amostra de Domicilios in Brazil and 2006 Encuesta Nacional de Salud y Nutrición in Mexico required medical diagnosis of a chronic condition.

${ }^{\mathrm{b}}$ Curative visit recall period for Mexico is two weeks.

${ }^{c}$ Preventive visit recall period for Peru is three months.

d Dentist visit recall period for Peru is four weeks; in Mexico it is two weeks and conditional on having had a health problem. 
$e_{h}=$ equivalence factor for household $h$, $A_{h}=$ number of adults in household $h$, $K_{h}=$ number of children, and $\Phi$ and $\theta=0.75$.

Explanatory variables included need and non-need variables. Self-assessed health, physical limitations, and chronic conditions are usually associated with need and were used as a proxy for health care need. Non-need variables included economic activity, education attainment, health insurance, rural or urban residence, geographic region, and ethnicity or race, among others described in Table 2. Non-need variables are not associated with the need to use health care services but should be included to reduce the potential threat from omitted variable bias. Including these variables also allows for analysis of the contribution of these factors to any observed inequity. This process is similar to that of assessing the role of intermediary factors and confounders in the analysis of an association (14).

\section{Analysis and explanation of horizontal inequity}

The methodology described here expands and complements the estimation techniques used previously to measure equity in Brazil, Ecuador, Jamaica, and Mexico (15) and it is similar to the methods used by van Doorslaer et al. (16) and described by O'Donnell et al. (17). Health inequality was calculated by first standardizing the health status variable by age and sex. The standardized distribution of the health variable was estimated by calculating the difference between actual and standardized (expected) health.

The horizontal inequity methodology calls for comparing the actual and the need-expected distribution to assess inequities in health care use. Incomerelated distribution of actual health care utilization reveals inequality in use, while need-standardized health care utilization reveals inequity in use (16). In the case of health care utilization, the utilization variable was standardized for health care need in addition to age and sex. Usually, health care need is proxied by self-assessed health status, chronic conditions, and physical limitations when available. The indirect standardization method is preferred over the direct standardization method, given its greater accuracy when dealing with individual-level data. Indirect standardization for health status and health care utilization is calculated as follows:

$$
\hat{y}_{i}^{I S}=y_{i}-\hat{y}_{i}^{X}+y^{m}
$$

where

$\hat{y}_{i}^{I S}=$ standardized health status or health care utilization,

$y_{i}=$ actual health status or health care utilization,

$\hat{y}_{i}^{X}=$ expected health status or health care utilization, and

$y^{m}=$ sample mean.

In the case of health care utilization, the need-expected utilization is computed in two steps. Actual health care utilization is calculated by running a linear ordinary least-squares regression, which regresses health care utilization $\left(y_{i}\right)$ on the logarithm of income (ln inc $c_{i}$ ), a vector of need variables $\left(\chi_{k}\right)$, and a vector of non-need variables $\left(\mathrm{Z}_{p}\right)$ as follows:

$$
y_{i}=\alpha+\beta \operatorname{lninc} c_{i}+\sum_{k} \gamma_{k} \chi_{k, i}+\sum_{p} \delta_{p} \mathrm{Z}_{p, I}+\varepsilon_{i}
$$

where

$\alpha, \beta, \gamma_{k^{\prime}}$ and $\delta_{p}=$ parameters, and $\varepsilon_{i}=$ error term.

By combining the coefficients from the estimation above with the actual values of the need variables $\left(\chi_{k}\right)$ selected for standardization, the sample mean values of the logarithm of income (ln inc $c_{i}$ ), and the sample mean values of the non-need variables $\left(\mathrm{Z}_{p}\right)$ selected to be controlled for, the need-expected health care utilization is obtained as follows:

$$
\hat{y}_{i}^{x}=\hat{\alpha}+\hat{\beta} \ln \operatorname{inc}^{m}+\sum_{k} \hat{\gamma}_{k} \chi_{k, i}+\sum_{p} \hat{\delta}_{p} \mathbf{Z}_{p}^{m}
$$

where

$$
\hat{\alpha}, \hat{\beta}, \hat{\gamma}_{k} \text {, and } \hat{\delta}_{p}=\text { parameters, and }
$$$$
m=\text { mean value. }
$$

Since health care utilization values, such as physician visits and number of inpatient days, are binary or non-negative integer counts and non-normally distributed dependent variables with data presenting a very skewed distribution in the latter case (due to a large number of zero observations), nonlinear models are more appropriate than linear models for the indirect standardization process. Nevertheless, while estimations generated by linear models may be less robust and precise than those generated by nonlinear models, evidence in the literature indicates that the results are similar $(16,17)$.

In addition, linear models offer advantages over nonlinear methods for calculating horizontal inequity measures; for example, control variables included in the regression can be entirely neutralized when generating the need predictions by setting them equal to their mean values, which improves the accuracy of the measurement, and contributions to any observed inequity can be assessed, which allows for separation of the contribution of each of the variables included in the model and assessment of their impact on utilization. The latter feature is very useful in decomposition, which allows for identifying factors that contribute to inequity (17).

The indices and distributions obtained with linear and nonlinear models were compared to confirm that the selection of a linear model would not affect the results. Given the advantages of using the linear model and the similarity of results with nonlinear models for all countries, preference was given to presentation of the results of the linear models.

Concentration indices were used to measure inequality and inequity. Inequality was measured with concentration indices of the unstandardized distribution (CI) of the dependent variable. Inequity was measured with concentration indices of the standardized distribution of the dependent variable, also known as the horizontal inequity index (HI). Therefore, the $\mathrm{HI}$ is a summary measure of the magnitude of inequity in the dependent variable, taking into consideration demographic factors such as age and sex or morbidity characteristics that are known to influence health status and utilization patterns across income groups.

$\mathrm{HI}$ is equivalent to the CI of the needstandardized dependent variable, which is the difference between the concentration index of actual distribution and the need-expected distribution (17). The average relationship between need and the dependent variable is used as the norm to assess horizontal inequity. Systematic deviations from the established norm were calculated for health status and health care utilization variables for at least two years in each country.

The CI can also be calculated by using a simple convenience covariance formula for weighted data, which is the 
covariance between the dependent variable and the rank in income distribution scaled by 2 and divided by the mean of the dependent variable (17), as follows:

$$
C I=\frac{2}{\mu} \operatorname{cov}_{w}\left(y_{i}, R_{i}\right)
$$

where

$\mu=$ weighted sample mean of $y$, $\operatorname{cov}_{w}=$ weighted covariance, and $R_{i}=$ relative fractional rank of $i$ th individual.

The relative fractional rank indicates the weighted cumulative proportion of the population up to the midpoint of each individual weight and is calculated as follows:

$$
R_{i}=\frac{1}{n} \sum_{j=1}^{i-1} w_{j}+\frac{1}{2} w_{i}
$$

where

$$
n=\text { sample size, and }
$$$$
w=\text { sampling weight. }
$$

HI values are calculated from samples, requiring the calculation of standard errors to test their statistical significance. Since these studies considered samples from different years, the $t$-statistics test was performed to calculate the statistical significance of the difference between the HI for each survey year.

Two important characteristics of the $\mathrm{CI}$ and its standardized version (HI) that should be noted are its aversion to inequality and its concentration curves. The CI includes an implicit parameter that indicates the level of society's aversion to inequality, which places an added weight on the health of the most disadvantage individuals. This parameter, which can be adjusted, weights the health of the most disadvantaged individuals by a factor of 2 and declines as socioeconomic rank increases (18).

The concentration curve displays the cumulative share of the dependent variable and the cumulative population ranked by socioeconomic position, such as income, expenditure, wealth, or any other variable that can be rank-ordered. Figure 1 shows a concentration curve for specialized health care visits, where socioeconomic position (horizontal axis) is represented by income, from the poorest (left) to the richest (right). The vertical axis shows the distribution of specialized health care visits. The diagonal line (red line) represents equality, a situation in which specialized health care visits are equally distributed among each income group. The concentration curve (blue) shows that the poorest $20 \%$ of the population (horizontal axis) accounts for only about $5 \%$ of specialized health care visits (vertical axis), while the richest $20 \%$ of the population accounts for about $60 \%$. This concentration curve shows a clear pro-rich distribution.

In addition to offering a graphic representation of $\mathrm{CI} / \mathrm{HI}$, the concentration curve also offers information that is not available with $\mathrm{CI} / \mathrm{HI}$ alone. When $\mathrm{CI} / \mathrm{HI}$ is zero, as explained below, it is usually interpreted as no inequity found, but it may also be the result of the distributions of the dependent variable and income. If the concentration curve crosses the line and the areas above and below the line are identical, the resulting index will be zero but the curves will clearly indicate the presence of inequality. But if the concentration index is zero and the curve is equal to the equality line, the distribution is equitable. Because it is important to distinguish both situations, CI/HI should be analyzed in combination with the concentration curve (17).

Concentration curves, concentration indices, and quintile distributions were presented for each study and dependent variable, since these results have distinct characteristics and may target different actions. Concentration curves are generated to identify income-related inequalities in the variable of interest, while concentration indices are computed to measure the magnitude of the inequality.

If systematic differences related to income are observed between the actual and the standardized dependent vari- able, horizontal inequity is detected. If the standardized concentration index is zero, the interpretation is that there is horizontal equity. A positive index indicates pro-rich inequity, while a negative index indicates pro-poor inequity.

Decomposition analysis is used to show the contribution of each variable in the analysis to the total inequality in a health care variable. According to O'Donnell et al. (17), if the health care utilization variable is specified as a linear function, then its concentration index can be decomposed into each determinant's contribution, allowing for explanation of horizontal inequity in health care utilization. It is noteworthy that linear models generate the same concentration/horizontal index when calculated with the two-step approach or through decomposition. But when a nonlinear model is used, the indices produced by these two approaches are not the same because of introduction of the linear approximation error (17).

The decomposition of the concentration index is calculated as the product of the health care variable elasticity with respect to each determinant and its concentration index, as follows:

$$
C=\sum_{k}\left(\frac{\beta_{k} \bar{x}_{k}}{\mu}\right) C_{k}+\frac{G C_{\varepsilon}}{\mu}
$$

where

$\mu=$ weighted sample mean of $y$,

$\beta_{k}=$ regression coefficient of determinant $k$,

$\bar{x}_{k}=$ mean of $\chi_{k^{\prime}}$

$C_{k}=$ concentration index for $\chi_{k}$, and

$G C_{\varepsilon}=$ generalized concentration index for the error term $(\varepsilon)$.

\section{FIGURE 1. Example of concentration curve of specialized health care visits}

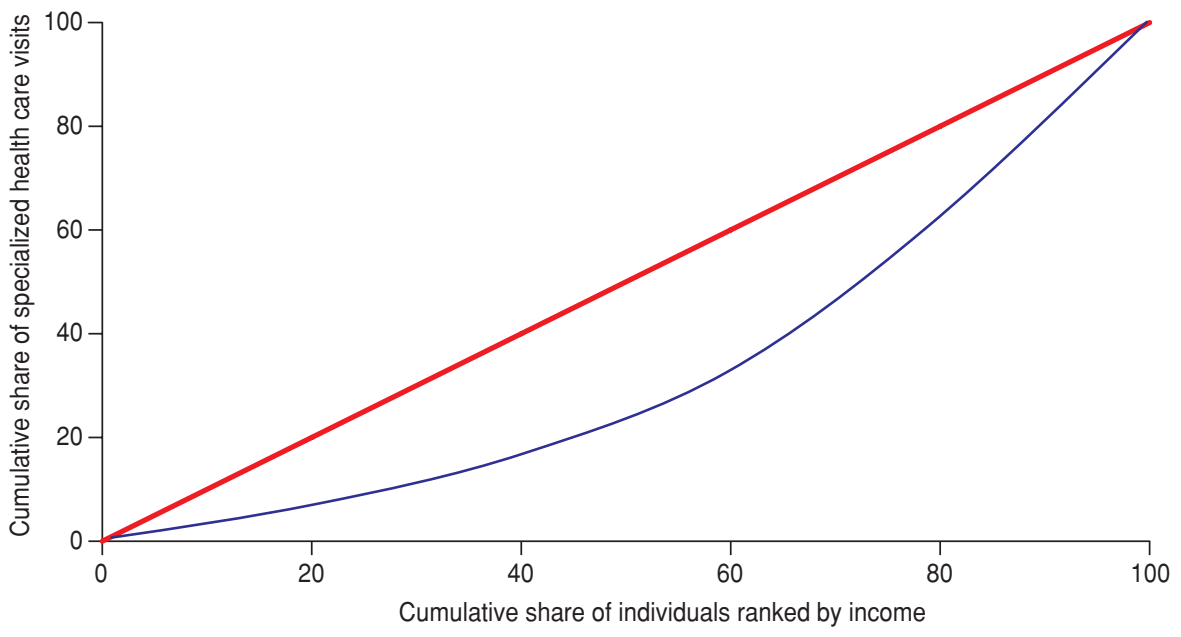


When sensitivity analysis of the concentration indices and distributions with linear and nonlinear models produce substantial differences, linear approximation can be used to estimate the partial effects with nonlinear methods for the decomposition process. As suggested in the literature, the decomposition is still possible with the linear approximation to the nonlinear model (16, 17). The previous formula still applies for the decomposition with linear approximation, if replacing $\beta_{k}$ by $\beta_{k}^{m}$, for the partial effects of each determinant.

The decomposition process of the concentration index provides important information about the contribution of each variable to the degree of inequality in health care utilization, allowing for the identification of which variables are the greater contributors to inequality. In addition, the calculated elasticity provides information on the impact of each variable on health care use and the concentration index provides information on the variable's distribution across income.

\section{RESULTS}

The results of the analysis of incomerelated inequality in health and health care in Brazil, Chile, Colombia, Jamaica, Mexico, and Peru are presented in other articles in this issue (19-24).

\section{DISCUSSION}

While health insurance coverage and economic activity were key determinants of health care utilization and therefore should be included as non-need determinants in the regression model, potential problems of moral hazard effect, adverse selection, and endogeneity can arise with the inclusion of these variables in the analysis (25). Moral hazard and adverse selection are well-known opportunistic behaviors of insurance consumers. The former describes a higher utilization of health services by insured individuals, while the latter refers to the fact that those expected to have more use of health services are more likely to buy health insurance.

Endogeneity can occur when an independent variable is correlated with the error term in a regression model, including when omitted variables that should be controlled for are not included in the model, usually because of unavailability of data, measurement error of one or more variables, or simultaneous determination of an explanatory variable and the dependent variable. An example of the latter occurs when health care utilization is partly determined by health insurance coverage or vice versa. Endogeneity is particularly relevant if a causal relationship is being investigated, in which case it should be explored with the use of a structural model capable of capturing a causal relationship. Alternatively, variables can be included in the initial model and endogeneity can be explored afterward (26).

The research studies that follow in this issue attempted not to draw causality but to effectively describe and explain incomerelated inequalities in health status and health care utilization over time with explanatory models. In other words, the research did not investigate whether income affects health or health care utilization but assessed whether distribution of the health status and health care utilization variables changes with distribution of income.

Potential methodologic issues may arise from the complexity of the surveys used. Data collected from complex surveys have different probabilities for the selection of sampling units, clusters, and strata. Therefore, the use of appropriate methods to analyze this type of data is essential for accurate calculation of estimates and to assess the precision of such estimates, which requires including information about the survey design and selection of a suitable method for calculating standard errors (27). In addition, the use of weights for data analysis serves to accurately repre- sent the different probabilities in the sample and to avoid biases in the results, especially if they are to be generalized (28). To avoid these problems, the studies utilized Stata commands to describe the study design and weights when appropriate. All but one study used Stata for data analysis; Jamaica applied ADePT software, which uses Stata for computations (29).

An important limitation of these studies was the use of self-reported income information, which is known to be underreported, especially among the rich (30). Consequently, the level of inequality in the distribution of income is usually higher than the levels presented with data collected from household surveys. Therefore, the level of horizontal inequity presented by these studies is probably underestimated.

The concentration index presented here is not free of errors. Recent studies have been published showing that the use of a concentration index may be affected by the magnitude of inequality and ranking among countries when the variable under investigation is binary (31-33). Some of the problems discussed in the literature are approached in an upcoming article comparing the findings of these six research studies. These studies are presented in this issue, with the results of the measurement of income-related inequality in health status and health care utilization for Brazil, Chile, Colombia, Jamaica, Mexico, and Peru, using the methodology described in this article.

Acknowledgment. The authors thank Heitor Werneck for his contributions to this study.

Funding. This study was funded by the Equity in Health Systems in Latin America and the Caribbean (EquiLAC) Project of the Pan American Health Organization.

Conflict of interest. None.

\section{REFERENCES}

1. Schneider MC, Castillo-Salgado C, Bacallao J, Loyola E, Mujica OJ, Vidaurre M, et al. Methods for measuring health inequalities (part III). Epidemiol Bull. 2005;26(2):12-5.

2. Ministers of Health of the Americas. Health agenda for the Americas 2008-2017. Panama City: Ministers of Health of the Americas; June 2007. Available from: http://www.
paho.org/English/DD/PIN/Health_ Agenda.pdf Accessed 18 May 2012.

3. Pan American Health Organization. Public health in the Americas: new concepts, performance analysis and bases for action. Washington, D.C.: PAHO; 2002.

4. Singh K. Quantitative social research methods. New Delhi: SAGE Publications; 2007. Pp. 64-5.
5. Adler ES, Clark R. An invitation to social research: how it's done. 4th ed. Belmont, California: Wadsworth, Cengage Learning; 2011. Pp. 157-7.

6. Centro de Documentação e Disseminação de Informações, Instituto Brasileiro de Geografia e Estatística. Pesquisa nacional por amostra de domicílios. Rio de Janeiro: CDDI/ IBGE; 1998, 2003, 2008. 
7. Gobierno de Chile, Ministerio de Planificación, Departamento de Información Social. Encuesta de caracterización socioeconómica nacional, 2000, 2003, 2009. Santiago: MIDEPLAN; 2000, 2003, 2009.

8. Colombia, Departamento Nacional de Estadística. Encuesta nacional de calidad de vida, 2003, 2008. Bogotá: DANE; 2003, 2007.

9. Planning Institute of Jamaica, Statistical Institute of Jamaica. Jamaica survey of living conditions. Kingston: PIOJ/STATIN; 2004, 2007.

10. Valdespino JL, Olaiz G, López-Barajas MP, Mendoza L, Palma $\mathrm{O}$, Velázquez $\mathrm{O}$, et al. Encuesta nacional de salud 2000. Tomo I: vivienda, población y utilización de servicios de salud. Cuernavaca, México: Instituto Nacional de Salud Pública; 2003.

11. Olaiz-Fernández G, Rivera-Dommarco J, ShamahLevy T, Rojas R, Villalpando-Hernández S, Hernández-Avila M, et al. Encuesta nacional de salud y nutrición 2006. Cuernavaca, México: Instituto Nacional de Salud Pública; 2006.

12. Peru, Instituto Nacional de Estadística e Informática. Encuesta nacional de hogares sobre condiciones de vida y pobreza. Lima: INEI; 2004, 2008.

13. Deaton A. The analysis of household surveys: a microeconometric approach to development policy. Baltimore: Johns Hopkins University Press; 1997. Pp. 241-70.

14. Wagstaff A, van Doorslaer E. Measuring and testing for inequity in the delivery of health care. J Hum Res. 2000;35(4):716-33.

15. Pan American Health Organization. Investment in health: social and economic returns. Washington, D.C.: PAHO; 2001. (Scientific and Technical Publication 582).

16. van Doorslaer E, Masseria C, OECD Health Equity Research Group. Income-related in- equalities in the use of medical care in 21 OECD countries. Paris: OECD; 2004.

17. O'Donnell O, van Doorslaer E, Wagstaff A, Lindelow M. Analyzing health equity using household survey data: a guide to techniques and their implementation. Washington, D.C.: World Bank; 2008.

18. Wagstaff A. Inequality aversion, health inequalities and health achievement. J Health Econ. 2002;21(4):627-41.

19. Almeida G, Sarti FM, Ferreira FF, Diaz MDM, Campino ACC. Analysis of the evolution and determinants of income-related inequalities in the Brazilian health system, 19982008. Rev Panam Salud Publica. 2013;33(2): 90-7.

20. Vásquez F, Paraje G, Estay M. Income-related inequality in health and health care utilization in Chile, 2000-2009. Rev Panam Salud Publica. 2013;33(2):98-106.

21. Ruiz Gómez F, Zapata Jaramillo T, Garavito Beltrán L. Colombian health care system: results on equity for five health dimensions, 2003-2008. Rev Panam Salud Publica. 2013;33(2):107-15.

22. Scott E, Theodore K. Measuring and explaining health and health care inequalities in Jamaica, 2004 and 2007. Rev Panam Salud Publica. 2013;33(2):116-21.

23. Barraza-Lloréns M, Panopoulou G, Díaz BY. Income-related inequalities and inequities in health and health care utilization in Mexico, 2000-2006. Rev Panam Salud Publica. 2013; 33(2):122-9.

24. Petrera M, Valdivia M, Jimenez E, Almeida G. Equity in health and health care in Peru, 2004-2008. Rev Panam Salud Publica. 2013; 33(2):131-6.

25. van Doorslaer E, Koolman X, Puffer F. “Measuring up": improving health system perfor- mance in OECD countries. Paris: OECD; 2002. Pp. 225-48.

26. Wooldridge JM. Econometric analysis of cross section and panel data. Cambridge, Massachusetts: MIT Press; 2002.

27. Skinner CJ, Holt D, Smith TMR, eds. Analysis of complex surveys. Chichester, New York: Wiley; 1989.

28. Stanford University. Complex survey design using Stata. Social science data and software. Available from: http://www.stanford.edu/ group/ssds/cgi-bin/drupal/files/Guides/ ComplexSurveyDesignUsingStata_0.pdf Accessed 4 January 2013

29. Wagstaff A, Bilger M, Sajaia Z, Lokshin $M$. Health equity and financial protection: streamlined analysis with ADePT software. Washington, D.C.: World Bank; 2011.

30. Székely M, Hilgert M. What's behind the inequality we measure: an investigation using Latin American data. Washington, D.C. Inter-American Development Bank; 1999. P. 11. (Working Paper 409).

31. Wagstaff A. Correcting the concentration index: a comment. J Health Econ. 2009;28(2): 516-20.

32. Kjellsson G, Gerdtham U. Correcting the concentration index for binary variables. Lund: Department of Economics, Lund University; 2011. (Working Paper 2011:4).

33. Erreygers G, Clarke P, Van Ourti T. "Mirror, mirror, on the wall, who in this land is fairest of all?" Distributional sensitivity in the measurement of socioeconomic inequality of health. J Health Econ. 2012;31(1):257-70.

Manuscript received on 6 June 2012. Revised version accepted for publication on 29 November 2012.

RESUMEN Objetivo. Describir la metodología usada para medir y explicar la evolución de las desigualdades en la salud y la utilización de la atención sanitaria relacionadas con los ingresos en países seleccionados de América Latina y el Caribe.

\section{Medición de la evolución de las desigualdades en la salud y la utilización de la atención sanitaria relacionadas con los ingresos en países seleccionados de América Latina y el Caribe}

Palabras clave
Métodos. Se utilizaron datos de encuestas nacionales de hogares representativas de Brasil, Chile, Colombia, Jamaica, México y Perú. La salud se midió mediante autoinformes del estado de salud, las limitaciones físicas y las enfermedades crónicas. Las hospitalizaciones y las consultas médicas, odontológicas, preventivas y curativas se emplearon como medición indirecta de la utilización de la atención sanitaria, y los ingresos del hogar como medición indirecta para estimar la situación socioeconómica en todos los estudios, excepto en el de Perú, donde se utilizaron los gastos de los hogares. Los índices de concentración se calcularon para todas las variables dependientes antes y después de su estandarización; los índices estandarizados de concentración también se mencionan como índice horizontal de inequidad. Se empleó el análisis de descomposición para identificar los determinantes principales de la desigualdad en la utilización de la atención sanitaria.

Resultados. Los resultados de los análisis de los seis países estudiados se presentan en artículos separados de este número de la revista.

Conclusiones. La metodología empleada para el análisis de la equidad en los seis estudios de país no intenta determinar la causalidad, sino describir y explicar la evolución de las desigualdades en el estado de salud y la utilización de la atención sanitaria relacionadas con los ingresos. Si bien esta metodología es sólida, no está exenta de errores, que se identificaron y se corrigieron, cuando fue posible.

Equidad en el acceso; equidad en salud; sistemas de salud; política de salud; América Latina; región del Caribe. 
REVISTA

PANAMERICANA

DE SALUD PÚBLICA
PAN AMERICAN

JOURNAL OF

PUBLIC HEALTH

Material suplementario / Supplementary material / Material supplementar

Supplementary material to:

\author{
Almeida G, Sarti FM, Ferreira FF, Diaz MDM, \\ Campino ACC. Analysis of the evolution and \\ determinants of income-related inequalities in the \\ Brazilian health system, 1998-2008. Rev Panam \\ Salud Publica. 2013;33(2):90-7.
}

This material formed part of the original submission and has been peer reviewed. We post it as supplied by the authors. 

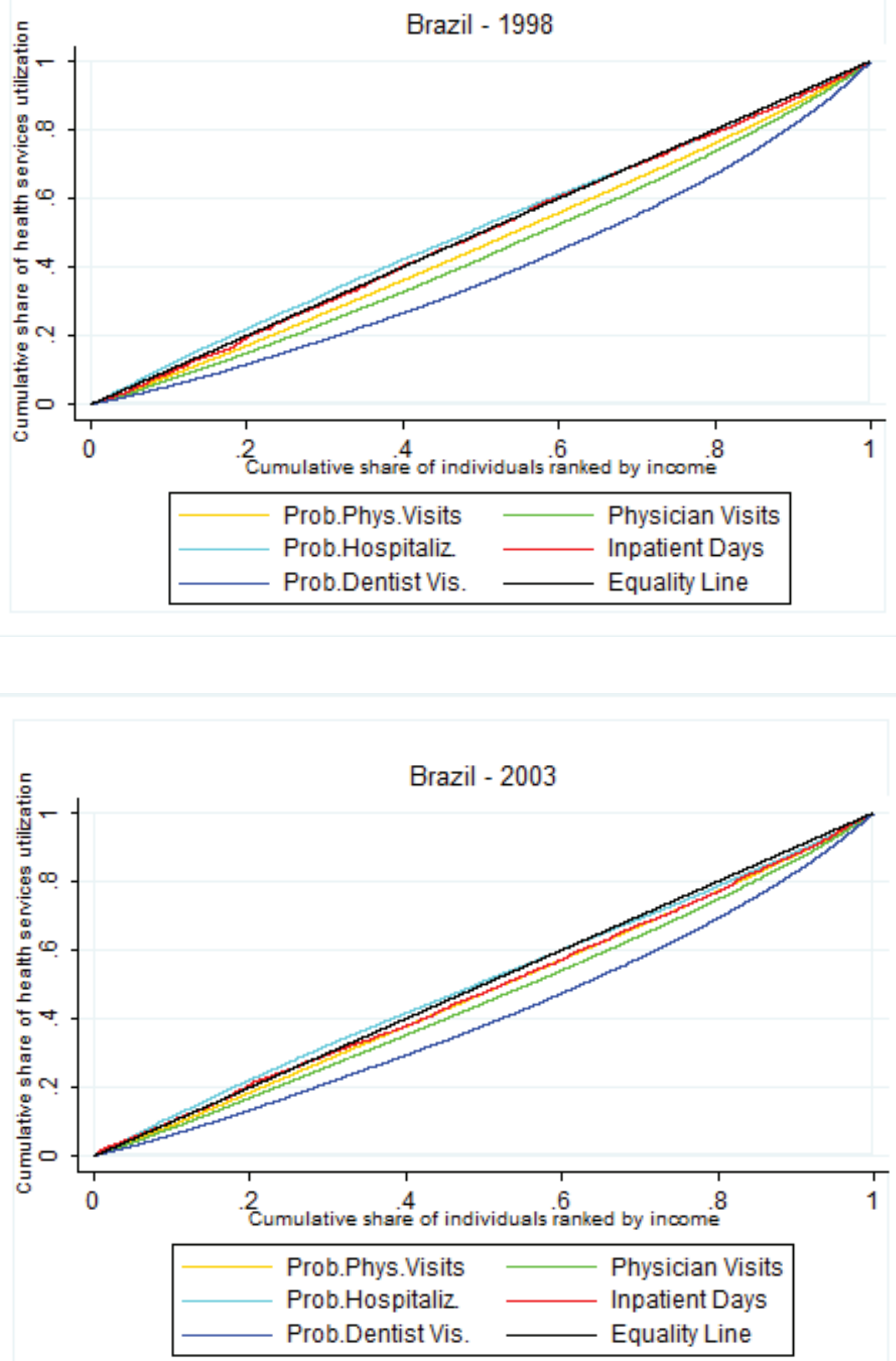

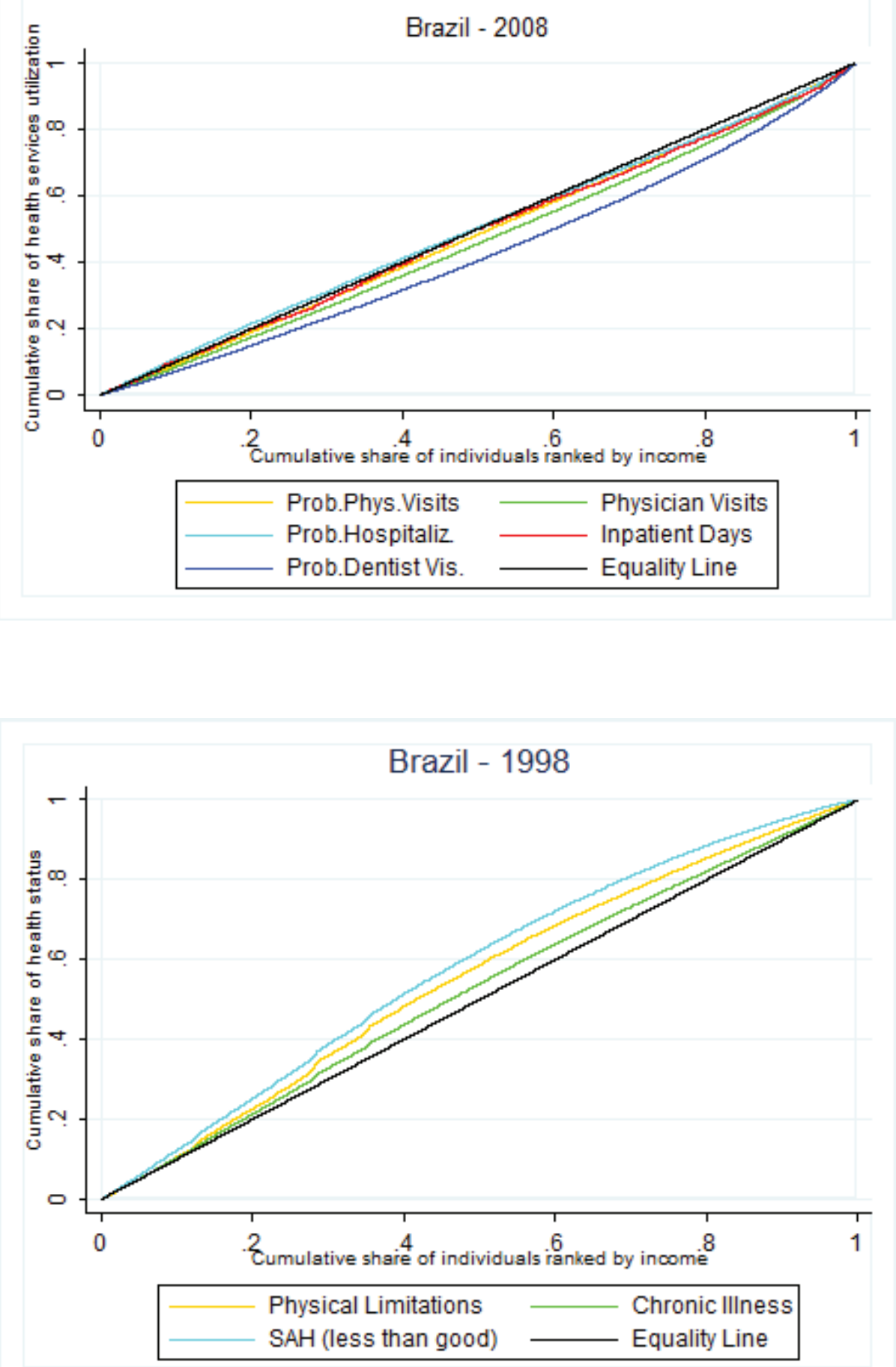

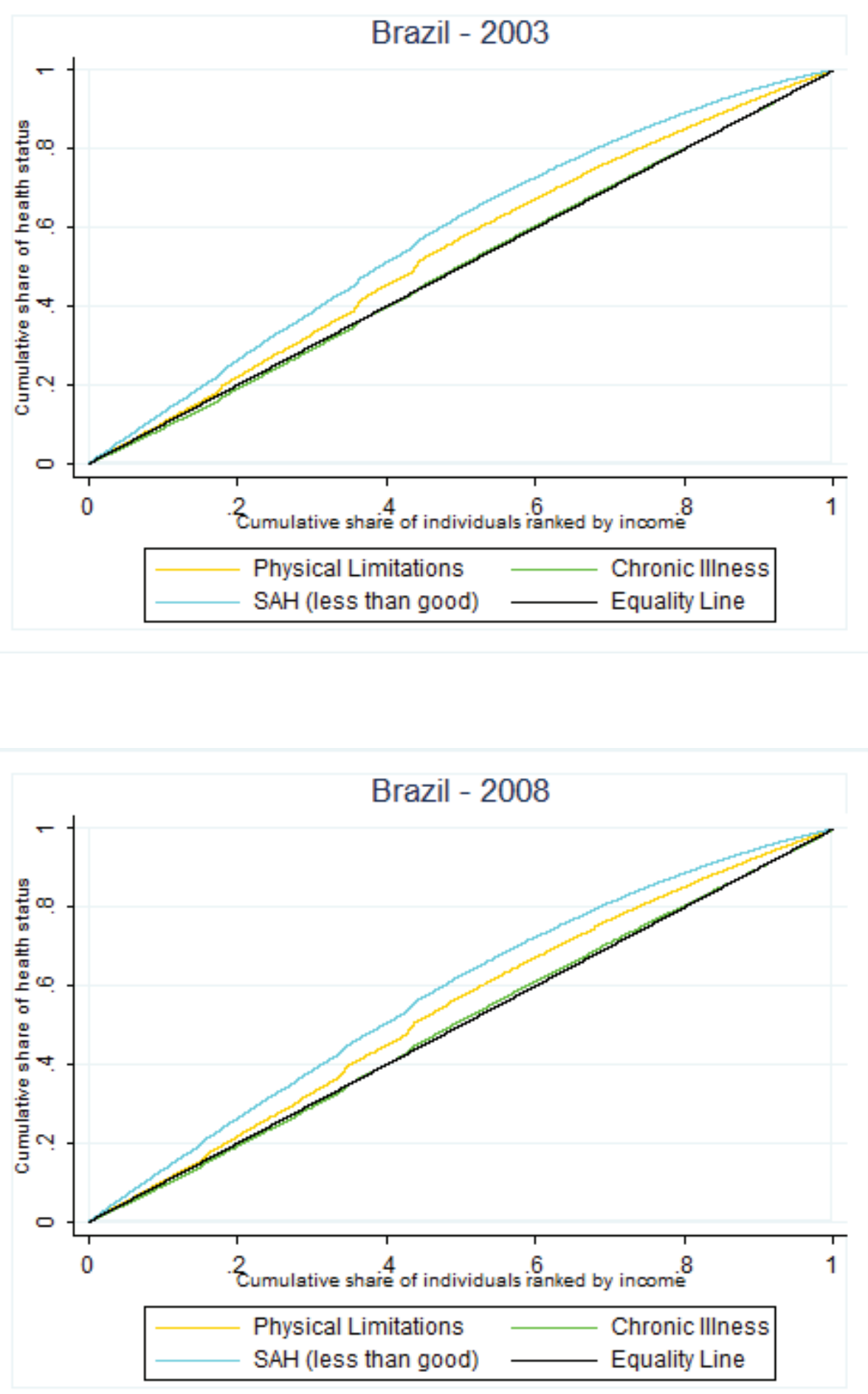